\title{
Parents' guide on life-skills for children in coronavirus disease times
}

\author{
Akumtoshi Pongen \\ Consultant Paediatrician and Neonatologist, Department of Pediatrics, Zion Hospital and Research Centre, Dimapur, Nagaland, India
}

\begin{abstract}
With the closedown of schools due to Coronavirus disease-19, children are likely to have poor scholastic achievement apart from the difficulty in social interaction and life-skills development. Pre-school is a crucial time as the brain is developing rapidly and learning during this stage sets the stage for future success. Therefore, parents need to step up to the occasion in the absence of teachers. It becomes a parent's responsibility to teach their children independence, resilience, social interactions, language, and appropriate usage of digital devices, and so on. A routine that includes games and activities that teach life skills is essential for the overall development of a child. This short article tries to guide parents so that no part of a child's development is left out.
\end{abstract}

Key words: Coronavirus disease, Life skills, School, Social skills

$\mathrm{T}$ he preschool period is a pivotal time for a child's physical and mental development. According to Centers for Disease Control and Prevention, pre-schooler include age groups from 3 to 5 years of age. The first 5 years of a child's life is crucial for the developing brain according to the United Nations Children's Fund since the experiences during this period are said to provide the base for the organizational development of the brain. It has a direct effect on how a child develops learning skills together with social and emotional maturity [1]. The social learning theory was conceived by Clark Hull an American psychologist who was also a research professor in the Institute of Psychology around 1930s at Yale University [2].

With schools closed down due to Coronavirus disease (COVID), children are at risk of inferior academic accomplishment and poor life skills and social interaction. Socializing happens naturally while being around their peers and other children. However, teaching social skills can be challenging when "social distancing" is to be maintained. Social skills along with peerto-peer interaction can get hampered and therefore it becomes a parent's (or a caregiver's) responsibility to impart important life skills at home - the ability to read emotions, cooperate, and negotiate conflicts, and so on.

Social interaction and development can be broadly classified into four types-

\section{Access this article online}

Received - 01 June 2021

Initial Review - 10 June 2021

Accepted - 28 June 2021

DOI: $10.32677 / \mathrm{IJCH} .2021 . v 08.107 .002$

\section{Independence}

Pre-school and school children learn to be independent during this stage. They learn how to put waste in the waste bin, how to arrange their toys properly after play, clean up after eating, arrange their clothes, keep their utensils clean, brush their teeth, potty training, pull up their pants after going to the washroom, etc. It may be a messy start but start nonetheless. Many children usually learn this in school rather than at home. It has been observed that, whenever parents start making their child work independently at home, they usually show some resistance.

Initially, parents are advised to help and guide them or work together till the child becomes independent. Bandura and Walters showed how a new behavior can develop in children, by just observing a role model which is usually parents. A child can also be influenced by a penalty or reward received by another child or sibling for the same conduct and can learn from it [3]. It is advised to provide them the liberty to be messy while eating or drinking and let them get things wrong sometimes with their toys while playing. Let them participate in gardening, pluck fruits from the kitchen garden and take care of pets at home.

Give them some autonomy for their skills to grow. Give them a chance to get up on their own when they fall over. Let children choose the toy to play with or the story to be read, which gives them a sense of responsibility and helps in independent decisionmaking. It is important to appreciate them whenever they perform certain activities independently, as this helps the child gain confidence. Make sure you don't praise them more than is

Correspondence to: Akumtoshi Pongen, Consultant Paediatrician and Neonatologist, Department of Pediatrics, Zion Hospital and Research Centre. Dimapur, Nagaland, India. Email: akumtoshi_official@yahoo.com

(C) 2021 Creative Commons Attribution-NonCommercial 4.0 International License (CC BY-NC-ND 4.0). 
required, as this may make the child expect the same inflated applause every time and everywhere. It takes patience and effort from both parties. It is our aim that they become independent, but without being a "helicopter parent" [4].

\section{Resilience}

It is the ability to bounce back after a disappointment or a failure. In the book "Anxious Kids, Anxious Parents" the author Reid Wilson, the Director of the Anxiety Disorders Treatment Centre says "We have become a culture of trying to make sure our kids are comfortable. We as parents are trying to stay one step ahead of everything our kids are going to run into." The reality is that "Life doesn't work that way [5]." Parents must teach them to overcome hurdles and handle unpredictability but it is not a parent's task to be there forever with their kids. For example, a parent may permit their 10-year-old kid to sleep in their bedroom because they feel uneasy to sleep on their own, which may hinder a child's psychological maturity.

Resilience may vary from child to child, while some children may need more guidance others may not. A parent or a caregiver has to understand that as uncomfortable as it may be, a child needs to realize the importance of getting things right eventually. It is paramount to make them appreciate the importance of recovering from a failure, rather than making them embarrassed or miserable about the situation. Instead of ready-made answers to problems, one can use the phrase "I don't know," "followed by promoting problem-solving," this can help kids to handle uncertainty and tackle potential challenges [5]. For example, if a child asks why a mango tastes sweet but lemon does not, you could say "I don't know. Why do you think so?"

Once they can do certain chores at home on their own, it boosts up their confidence and helps them take up more tasks and responsibilities on their own. There is no perfect way to achieve this, other than a parent-child partnership. The "helicopter parenting" attitude sometimes delays a child's developmental process; instead, getting out of the way in a certain situation may work out best. Simultaneously, they should learn that knowing when to ask for help is being courageous and not weak. Often being observed that a child is more resilient and responsible at school than at home, which is usually because a child is given more independence at school. It is good to have a structured routine at home, especially with the school being shut due to COVID. Have a fixed time for going to bed and getting up. Caregivers need to be role models and participate in the routine to encourage the child, as children are more of imitators [4].

\section{Peer to peer social and language development}

The way children interact with adults is different from how they interact among themselves. Inadequate attention to children during this age group can cause catastrophe in a child's life. Peerto-peer relation in children starts very early in life when infants look at each other and react to each other's joy and sorrows.
Infants begin to communicate by the end of one year and start sharing, engaging in conflicts, and can make relationships with peers [6]. Parents can teach them techniques of social interaction by teaching them how to listen to others, how to make a conversation with others by modeling for them. Improving their emotional quotient by teaching children how to care for others or their relatives at home helps. One way to develop this is by playing "Emotion charades" for young children as developed by researchers at the University of Wisconsin-Madison. In this play, one player makes a certain face suggesting a certain emotion, and the others guesses what is the feeling portrayed. This introduces a variety of human emotions to a child and teaches them how to react in different circumstances. One can also introduce "pretend play" that helps to improve emotional self-regulation in children as found by Goldstein and Lerner in a randomized experiment on pre-schooler [7].

"Healthy lifestyle through home gardening" published in the American Journal of Lifestyle Medicine shows how gardening can generate social interactions among family members and the social, psychological, and physical health benefits of home gardening. With schools closed, having time for gardening becomes easier and this activity bonds individuals together, encourages a healthy lifestyle in children, brings joy, and healing to them and build up social relationships, trust, and sharing [8]. Simultaneously, reading books helps in the intellectual growth of a children when they are gradually taught to critically analyze the moral of a story. It is essential to let children run through the feelings of their friend or a family member under different circumstances which teaches them empathy. For example, when a child is sad because one of the siblings has eaten their candy, parents can teach them that it is exactly how another person would feel if they do the same. Children can be made to understand that it is okay to be wrong at times and to accept failures and to build on them for future success. It is the right time to teach them when to say thank you and sorry. This can easily be taught at home by telling them "thank you" when they bring something that you have asked them to bring and say "sorry" to them when mistakes are made [4].

Although the digital era has advanced human connection and knowledge extraordinarily, it has introduced certain downsides as well. A study showed that by 2 years of age, $89 \%$ of children had touched the screen of mobile gadgets and $77 \%$ had used apps [9]. With schools being closed, children are even more frequently exposed to smartphones or handheld devices and are at risk of delayed speech and language [10]. It has been shown that children exposed to prolonged use of electronic gadgets have poorer communication skills and social adjustment [11]. Therefore, parents need to be aware of the age-appropriate limits of using these gadgets in children, especially during these pandemic times. American Academy of Paediatrics recommends no screen time at all for children until 24 months, except for video chatting. Parents should co-view media with their kids and monitor the contents and duration. This, in long term, helps children to develop their language and communication skills while harnessing the benefits 
of a digital device such as online classes, communicating, and keeping in touch with friends and family.

\section{Sharing and Taking Turns}

Children usually learn how to share by about 3 years of age, with few exceptional cases. A parent's task is to make this transition easier and more enjoyable. Parents can try solving a jigsaw puzzle together, which will make the child realize that it is perfectly normal if their siblings or friends play with their toys for a while and their friends will also share toys with them. Parents can also mention an incidence of how another sibling was "sharing" toys which was appreciable. Sometimes it is embarrassing to see one's child grabbing a toy, or fuming because his turn has ended. In this situation if you tell your child that they are "self-centered," the child may get the wrong impression that sharing has disadvantages. It is acceptable for a child to have one or two favorite items which may be exempted from sharing with others.

Teach them to wait for their turn at home that prepares them for a better peer-peer interaction when they come in contact with other children. We can teach them to say "can I have the toy once you are done playing" which further improves their communication skill and patience at the same time. In turn, a parent or the elder sibling can show their appreciation for waiting patiently for their turn. This teaches them how to appreciate others. A simple game of cricket can be played at home using a plastic "bat and ball" by taking turns for batting and balling, this can be both enjoyable as well as a learning process of taking turns. Many children live in their grandparent's house in India along with their parents and a common local game like a "ludo" or "carrom board" can engage the entire household that can teach a child to take turns and accept defeat. Make sure that they also learn to take turns during a conversation, which actually can be modeled by the parents. Parents can involve children in a normal family conversation and teach them to listen without interrupting [4].

It is important to recognize that each parent/caregiver should be consistent in the practice of disciple or guidance if there is more than one caregiver. "Dolphin" Parenting is a way to convert resilience to self-motivation. Dolphin parents although authoritative are effective at encouraging self-motivation by allowing independence while still giving guidance. One way is to reward "effort" despite failing and not just when successful. Focusing on problem-solving rather than problems helps to build confidence and self-motivation. Children should be taught to practice gratitude and focus on the positive aspects of life, morality, and manners. Finally, there is nothing like a "perfect parent" and it is an evolving skill that is learned lifelong.

\section{RECOMMENDATIONS AND KEY POINTS}

- Teach children to be independent by involving them in simple household chores and tasks

- Help them deal with disappointments during play and teach them resilience

- Demonstrate empathy, sharing, and taking turns in the form of games

- Discipline them to listen without interrupting and have conversations by modeling for them

- Impart appropriate manners and greetings

- Maximize the benefits of digital gadgets but avoid inappropriate and excessive use.

\section{REFERENCES}

1. Facts for Life Child Development and Early Learning; 2021. Available from: https://www.unicef.org/ffl/03. [Last accessed on 2021 May 25].

2. Kihlstrom J, Hull CL. Encyclopedia of Personality and Individual Differences. Springer: Cham; 2018. p. 1-4.

3. Ho M, MacGlashan J, Littman M, Cushman F. Social is special: A normative framework for teaching with and learning from evaluative feedback. Cognition 2017;167:91-106.

4. Silvestro S. How to Help Kids Develop Social Skills at Home Preschool Teacher and Pediatrician's Tips; 2020. Available from: https://www.youtube. com/watch?v=ejQcjTW34Q0. [Last accessed on 2021 May 24].

5. Wilson R, Lyons L. Anxious Kids, Anxious Parents. Health Communications Inc; 2013.

6. Hay DF, Caplan M, Nash A. The beginnings of peer relations. In: Bukowski WM, Laursen B, Rubin KH, editors. Handbook of Peer Interactions, Relationships, and Groups. New York: The Guilford Press; 2018. p. 200-21.

7. Goldstein TR, Lerner MD. Dramatic pretend play games uniquely improve emotional control in young children. Dev Sci 2018;21:e12603.

8. Eng S, Khun T, Jower S, Murro M. Healthy lifestyle through home gardening: The art of sharing. Am J Lifestyle Med 2019;13:347-50.

9. Rideout VJ. Zero to Eight: Children's Media Use in America 2013. Pridobljeno; 2013.

10. Junco R. In class multitasking and academic performance. Comput Hum Behav 2012;28:2236-43.

11. Lissak G. Adverse physiological and psychological effects of screen time on children and adolescents: Literature review and case study. Environ Res 2018; $164: 149-57$.

Funding: None; Conflicts of Interest: None Stated.

How to cite this article: Pongen A. Parents' guide on life-skills for children in coronavirus disease times. Indian J Child Health. 2021; 8(7):243-245. 